\title{
Smart Sensor Network-Based Autonomous Fire Extinguish Robot Using IoT
}

\author{
https://doi.org/10.3991/ijoe.v17i01.19209 \\ D. Radha $(\bowtie)$ \\ HKBK College of Engineering, Bengaluru, India \\ radhad10391@gmail.com \\ M. Arun Kumar, Nagarjuna Telagam \\ Gitam University, Bengaluru, India \\ M Sabarimuthu \\ Kongu Engineering College, Tamil Nadu, India
}

\begin{abstract}
Fire explosion is among the main reasons for death in the world. The urban spaces have a lot of population, many systems have control over fire detection but not over control of fire due to lack of functionalities. The operation of the robot depends on the android application on the smartphone. It can also be communicated using Wireless fidelity technology. The motion detection technology is embedded in it, which can identify the objects or obstacles. With Arduino microcontroller and IoT technology, this robot can send emergency alerts in critical conditions, explore the compounds, and effectively check for the fire. The entire robot was contained in the sensor-based network, and if the sensors fail to detect, the robot still will operate and extinguish the fire with the help of an inbuilt camera. Finally, this robot is tested for operation in automated mode and live video buffering capability.
\end{abstract}

Keywords-Arduino, camera, sensor, IoT, Robot

\section{Introduction}

Many people work in a preserved environment in day-to-day life, many organizations and many more families face the hazardous fire. It is directly related to health loss and property loss; thus, fire detection systems are essential. Not useful in most situations. The motion control in robotics is divided into sensor-based and vision-based technologies [1]. The intelligent home-based fire detection system is explained [2]. The advanced security-based robot is designed in the United Kingdom with high fire extinguishing properties [3]. The intelligent multi-sensor-based security system for firefighting robot is developed [4]. The same PID Controller is used in a robotic system, which adjusts dynamically to the errors and the size and weight of robots in present conditions [5]. The image processing algorithms and device controlling algorithms are used to detect the Fire [6]. The safety of railways and road tunnels is broadly explained 
in robotic systems and significant infrastructures [7]. The detection of candle fame with sensors' help and extinguish the fire are presented with design [8]. Dangerous gases like carbon dioxide and nitrogenous oxide can be detected in spaces hidden from extinguishers [9]. The obstacle detection and avoidance are explained using ultrasonic sensors in large fire fields where high-temperature situations, anti-jamming processing are designed [10]. The PID controller-based backpropagation neural networks is proposed to adjust the error rate parameters in the real-time robot controller [11]. The industrial robots are designed with specific materials, divisions, gadgets [12]. Following the Fourth Industrial Revolution (4IR), there is interest in one framework that can control, convey, and coordinate various robots paying little heed to their sorts and determinations [13]. The robot can be isolated into a few gatherings, for example, Tele-robots, Telepresence robots, Mobile robots, Autonomous Robots, and Androids robots. [14]. A versatile robot is intended to explore and do undertakings with the mediation of people [15]. In the interim, self-governing robots can autonomously play out the performance and get the earth's force, instead of android robots that are worked to impersonate people [16]. The smart sensor network is designed for air pollution monitoring [20], temperature monitoring in VI server [17], fire rescue system [18], atm management [19], the UAV designed is used for sowing seeds are taken as a reference [20].

\section{The Proposed System}

The proposed robot will able to receive commands and react according to that in manual mode. The authorities may be timed or done manually. This smart robot can be connected with a remote using the help of Wi-Fi. An android app is developed to control the functionalities of the robot. Our robot has a unique function to detect the quantity of coolant present as backup whenever the coolant pressure is low; it sends an alert message to the mobile application. It uses the flame sensor for detection. The robot can move while also scanning for obstacles, which might turn out to be dangerous, sensors perform this scanning, robots helping as firefighters have not been implemented, and dedicated equipment that can already be used for such applications. Our robot can be sent into the danger zone to scan and extinguish. 


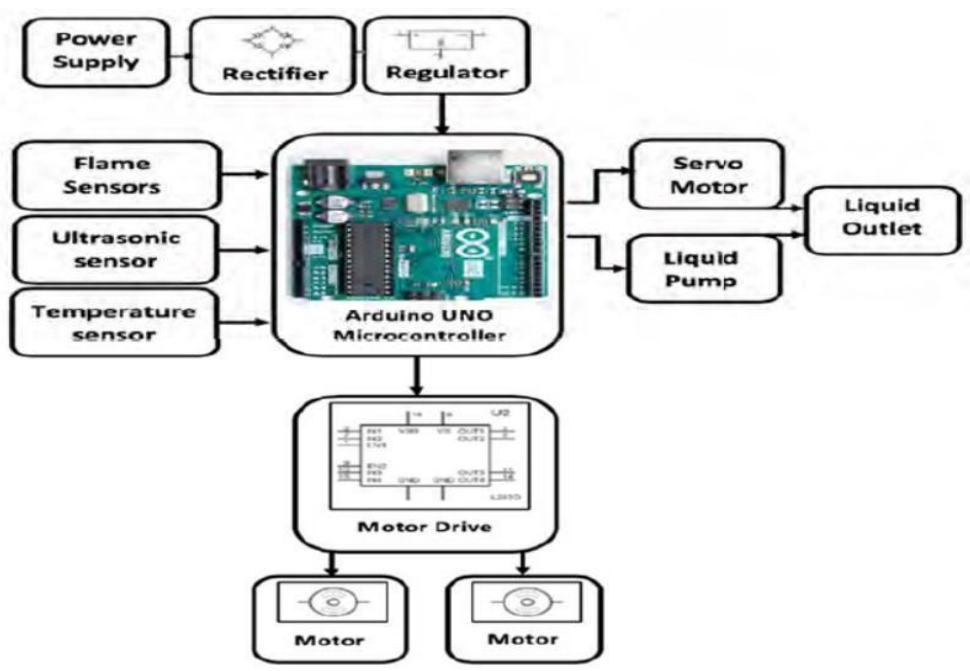

Fig. 1. Block diagram of the proposed system

Larger bots can be sent with more coolant capacity in them. The robot is implemented in situations where it is hazardous for firefighters to enter. It can detect the fire, and it can maneuver accordingly. It can detect and avoid obstacles autonomously. It regularly takes images of the danger zone at intervals, and it forwards the images to the controller. The android app is easy to use and is thus user friendly. In this system, the methodology has three parts. All parts were combined to obtain the function of fire detection, controlling it by extinguisher and gaining knowledge of the robot's behavior. Part one is the mechanical structure design of the robot's body. Part two is the implementation of the hardware parts used, and the third one is the design of the software and its details. Several electronic components are used to develop this: sensors, DC motors, Motor Driver L293D, servo motors, and pump with Arduino UNO, flame sensor, ultrasonic sensor, temperature sensor, and pump for pumping the liquid which is inside the tank.

The explainable diagram is shown in figure 1 below. Functional Requirements: Robot Automation Description and Priority Predictions will be made based on the sensors' data. These predictions will give the user the idea to turn the Motor on through the android application and without human intervention. The highest priority is given to automation. Response Sequences According to the obstacle detection, the fireman will decide whether to turn the robot to the left or right. As obstacles will be detected, the robot will function accordingly. If the fire is detected, the microcontroller will send a command to the sprinkler for turning it on. Then splinter will sprinkle water to extinguish the fire. 


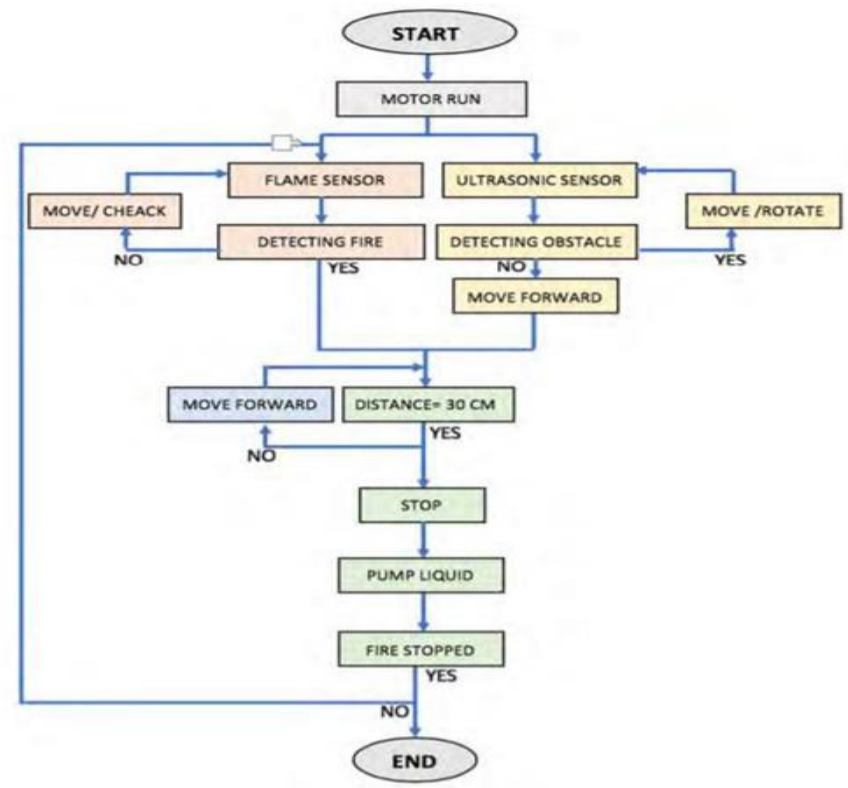

Fig. 2. Flow chart of the proposed system

\section{Implementation}

The procedure is described in the flow diagram shown in figure 2. if temperature sensors are added, more accurate results can be achieved from the incident. All these sensors are connected to an Arduino UNO and the pump with motors used to control the robot's 360-degree rotation. If the fire's flame sensor detects the fire, the Motor will stop at $35 \mathrm{~cm}$ away from the fire and start to flush and push the fluid towards the fire source noticed.

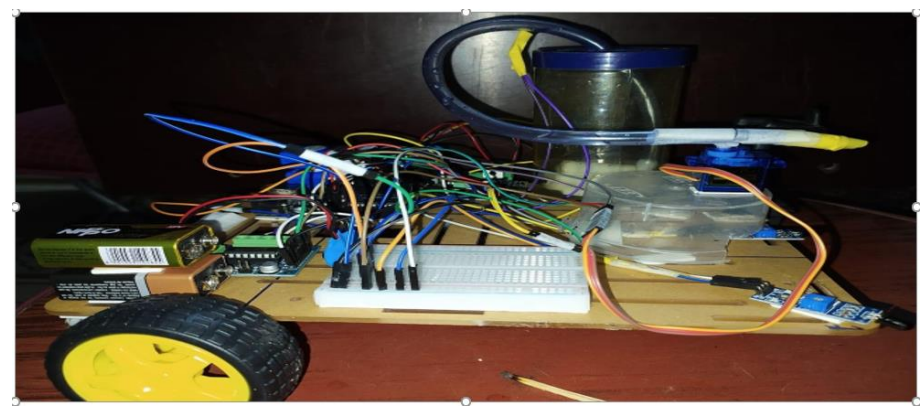

Fig. 3. Side View of Fire Fighting robot 


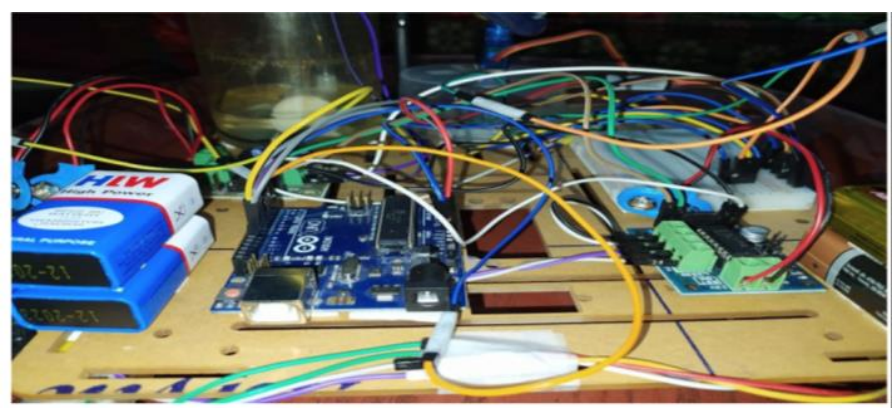

Fig. 4. Top View of Fire Fighting robot

\subsection{Programming}

Programming is the core element in building an autonomous robot that can make its own decisions using sensors as feedback.

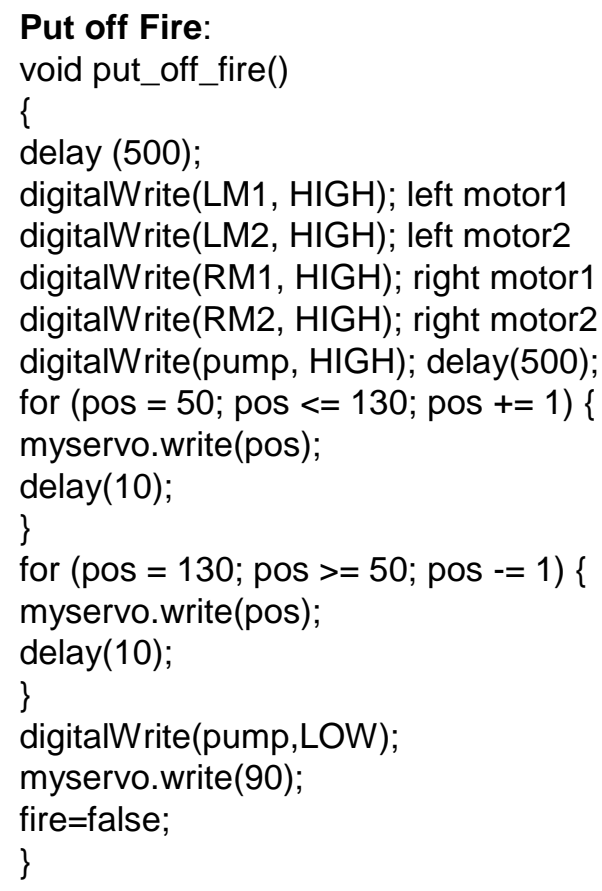

\subsection{Unit testing}

Unit testing is a typical practice in programming improvement where you fundamentally test code units to watch that they function true to form. Those units are standard techniques for your code, unmistakably worked in a specific assignment, such as playing out a particular estimation or parsing info. Your test code will, at that point, pressure 
that strategy with various data sources and check if the yield coordinates the usual worth.

Table 1. Video Feed Test

\begin{tabular}{|l|l|}
\hline Test Case \# & 1 \\
\hline Test Case Name & Video Feed Test \\
\hline Description & To test if the camera is taking in capturing the video through the application \\
\hline Expected Output & Video feed visible in the android app \\
\hline Actual Output & Video feed visible in the android app \\
\hline Remarks & Pass \\
\hline
\end{tabular}

Table 2. Bluetooth Module Test

\begin{tabular}{|l|l|}
\hline Test Case \# & 2 \\
\hline Test Case Name & Bluetooth Module Test \\
\hline Description & $\begin{array}{l}\text { To test if the Bluetooth module is taking in the input from the application by } \\
\text { connecting the phone to the device }\end{array}$ \\
\hline Expected Output & Successfully connecting \\
\hline Actual Output & Successfully connecting \\
\hline Remarks & Pass \\
\hline
\end{tabular}

Table 3. Motor Test

\begin{tabular}{|l|l|}
\hline Test Case \# & 3 \\
\hline Test Case Name & Motor Test \\
\hline Description & To test if the Motor after connected to the Arduino and power supply \\
\hline Expected Output & Successfully working \\
\hline Actual Output & Successfully working \\
\hline Remarks & Pass \\
\hline
\end{tabular}

\subsection{Integration testing}

Table 4. Video Stream Test

\begin{tabular}{|l|l|}
\hline Test Case \# & 4 \\
\hline Test Case Name & Video Streaming Test \\
\hline Description & $\begin{array}{l}\text { To test, the android application can take in the connect with the second phone } \\
\text { through the hotspot }\end{array}$ \\
\hline Expected Output & Successfully connecting \\
\hline Actual Output & Successfully connecting \\
\hline Remarks & Pass \\
\hline
\end{tabular}


Table 5. Controlling the Motor using the Bluetooth Input

\begin{tabular}{|l|l|}
\hline Test Case \# & 5 \\
\hline Test Case Name & Controlling the Motor using the Bluetooth Input \\
\hline Description & $\begin{array}{l}\text { The Android application sends a command to the Bluetooth module, which makes } \\
\text { the Motor Spin }\end{array}$ \\
\hline Expected Output & Successfully Spinning all 4 motors \\
\hline Actual Output & Successfully Spinning all 4 motors \\
\hline Remarks & Pass \\
\hline
\end{tabular}

Table 6. Controlling the movement of the Bot

\begin{tabular}{|l|l|}
\hline Test Case \# & 6 \\
\hline Test Case Name & Controlling the movement of the Bot \\
\hline Description & Using the application to move the bot after attaching the wheels on the Motor \\
\hline Expected Output & Successfully Spinning all 4 wheels \\
\hline Actual Output & Successfully Spinning all 4 wheels \\
\hline Remarks & Pass \\
\hline
\end{tabular}

Table 7. Controlling the direction of the Bot

\begin{tabular}{|l|l|}
\hline Test Case \# & 7 \\
\hline Test Case Name & Controlling the direction of the Bot \\
\hline Description & Using the application to move the bot to the desired direction \\
\hline Expected Output & Direction Changed \\
\hline Actual Output & Direction Changed \\
\hline Remarks & Pass \\
\hline
\end{tabular}

Table 8. Detecting the fire using the IR Sensor

\begin{tabular}{|l|l|}
\hline Test Case \# & 8 \\
\hline Test Case Name & Detecting the fire using the IR Sensor \\
\hline Description & Testing if the IR sensor can notify the application about the fire \\
\hline Expected Output & Notification Received \\
\hline Actual Output & Notification Received \\
\hline Remarks & Pass \\
\hline
\end{tabular}

Table 9. Liquid Release mechanism

\begin{tabular}{|l|l|}
\hline Test Case \# & 9 \\
\hline Test Case Name & Liquid Release mechanism \\
\hline Description & Using the Application to Douse the Fire using the spray \\
\hline Expected Output & Spray successfully Released \\
\hline Actual Output & Spray successfully Released \\
\hline Remarks & Pass \\
\hline
\end{tabular}

\section{Conclusion}

Firefighters are courageous and risk their lives whenever a fire occurs. Our robot will bring down the fires by going into the Fire hazardous zones remotely, controlled, 
or autonomously, thereby reducing firefighters' risk. Environmental awareness is a crucial aspect of this project, and our robot was made with that in mind. Our robot detects, avoids, and douses the fires around it with its many temperatures and proximity sensors. With its image processing capabilities, the robot can identify and avoid any obstacles that may be in the way of its objective to douse the fires. The overall total costing for the project will be of 63 US Dollars around. It can be used in places with the small entrance or small gaps because it's a compact structure.

\section{$5 \quad$ References}

[1] E. Krasnov and D. Bagaev, "Conceptual analysis of firefighting robots' control systems," 2012 IV International Conference "Problems of Cybernetics and Informatics" (PCI), Baku, 2012, pp. 1-3. https://doi.org/10.1109/icpci.2012.6486328

[2] K. L. Su, "Automatic Fire Detection System Using Adaptive Fusion Algorithm for Fire Fighting Robot," 2006 IEEE International Conference on Systems, Man and Cybernetics, Taipei, 2006, pp. 966- 971. https://doi.org/10.1109/icsmc.2006.384525

[3] A. Bradshaw, "The UK Security and Fire Fighting Advanced Robot project," IEE Colloquium on Advanced Robotic Initiatives in the UK, London, 1991, pp. 1/1-1/4.

[4] T. L. Chien, H. Guo, K. L. Su and S. V. Shiau, "Develop a Multiple Interface Based Fire Fighting Robot," 2007 IEEE International Conference on Mechatronics, Kumamoto, 2007, pp. 1-6. https://doi.org/10.1109/icmech.2007.4280040

[5] T. Rakib and M. A. R. Sarkar, "Design and fabrication of an autonomous firefighting robot with multi-sensor fire detection using PID controller," 2016 5th International Conference on Informatics, Electronics and Vision (ICIEV), Dhaka, Bangladesh, 2016, pp. 909- 914. https://doi.org/10.1109/iciev.2016.7760132

[6] J. H. Hwang, S. Jun, S. H. Kim, D. Cha, K. Jeon and J. Lee, "Novel fire detection device for robotic fire-fighting," ICCAS 2010, Gyeonggido, 2010, pp. 96-100. https://doi.org/10. 1109/iccas.2010.5669964

[7] L. Celentano, B. Siciliano and L. Villani, "A robotic system for firefighting in tunnels," IEEE International Safety, Security and Rescue Robotics, Workshop, 2005., Kobe, 2005, pp. 253-258. https://doi.org/10.1109/iccas.2010.5669964

[8] D. J. Pack, R. Avanzato, D. J. Ahlgren and I. M. Verner, "Firefighting mobile robotics and interdisciplinary design-comparative perspectives," in IEEE Transactions on Education, vol. 47, no. 3, pp. 369-376, Aug. 2004. https://doi.org/10.1109/te.2004.825547

[9] M. Sato, H. Torikai and Y. Iwatani, "Flame extinguishment by a prototype of an aerial extinguisher with an inert gas capsule," The SICE Annual Conference 2013, Nagoya, Japan, 2013, pp. 2051-2056.

[10] Tong feng, Xu Lufeng and Tong Daoling, "An ultrasonic obstacle avoidance system for firefighting robot," Proceedings of the 4th World Congress on Intelligent Control and Automation (Cat. No.02EX527), 2002, pp. 1219-1222 vol.2. https://doi.org/10.1109/wcica. 2002.1020775

[11] M. Li-xin, S. Dao-nian, C. Min-xuan, and W. Xiao-qin, "Application of Intelligent PID Control for Robot", IEEE Conference on Cybernetics and Intelligent Systems, pp. 455-458, 21 24 Sept. 2008.

[12] Jeelani, S., et al., Robotics and medicine: A scientific rainbow in hospital. Journal of Pharmacy \& Bio allied Sciences, 2015. 7(Suppl 2): p. S381-S383. 
[13] J. Lee, G. Park, J. Shin and J. Woo, Industrial robot calibration method using denavit Hatenberg parameters, 17th International Conference on Control, Automation and Systems (ICCAS), 2017, pp. 1834-1837. https://doi.org/10.23919/iccas.2017.8204265

[14] Tanaka, F., et al., Telepresence robot helps children in communicating with teachers who speak a different language, in Proceedings of the 2014 ACM/IEEE international conference on Human-robot interaction. 2014, ACM: Bielefeld, Germany. p. 399-406. https://doi.org/10.1145/2559636.2559654

[15] J. Ahn and G. J. Kim, Remote collaboration using a tele-presence mobile projector robot tele-operated by a smartphone, IEEE/SICE International Symposium on System Integration (SII), 2016, pp. 236- 241. https://doi.org/10.1109/sii.2016.7844004

[16] Harik, E.H. and A. Korsaeth, Combining Hector SLAM and Artificial Potential Field for Autonomous Navigation Inside a Greenhouse. Robotics, 2018. 7(2): p. 22. https://doi.org/10. 3390/robotics 7020022

[17] H. Hyung, B. Ahn, B. Cruz and D. Lee, Analysis of android robot lip-sync factors affecting communication, 11th ACM/IEEE International Conference on Human-Robot Interaction (HRI), 2016, pp. 441-442. https://doi.org/10.1109/hri.2016.7451796

[18] Telagam, Nagarjuna, Nehru Kandasamy, and Menakadevi Nanjundan. "Smart Sensor Network Based High Quality Air Pollution Monitoring System Using Labview." International Journal of Online and Biomedical Engineering (iJOE) 13, no. 08 (2017): 79-87. https://doi.org/10.3991/ijoe.v13i08.7161

[19] Telagam, Nagarjuna, Nehru Kandasamy, Menakadevi Nanjundan, and T. S. Arulanandth. "Smart Sensor Network based Industrial Parameters Monitoring in IOT Environment using Virtual Instrumentation Server." International Journal of Online and Biomedical Engineering (iJOE) 13, no. 11 (2017): 111-119. https://doi.org/10.3991/ijoe.v13i11.7630

[20] Nagarjuna Telagam, Sunita Panda, Nehru Kandasamy, Menakadevi Nanjundan, "Smart Sensor Network Based Fire Rescue System Design using LabVIEW", International Journal of Recent Technology and Engineering, Volume-8 Issue-2, July 2019https://doi.org/10. 35940/ijrte.b3010.078219

[21] Nagarjuna Telagam, Sunita Panda, Nehru Kandasamy, Menakadevi Nanjundan, "Smart Sensor Network Based Atm Management System using Lab view", International Journal of Engineering and Advanced Technology, Volume-8 Issue-5, June 2019

[22] Kumar, M. A., Telagam, N., Mohan Kumar, N., Ismail, K. M. and Rajasekar, T. (2020). Design and Implementation of Real-time Amphibious Unmanned Aerial Vehicle System for Sowing Seed Balls in the Agriculture Field. International Journal on Emerging Technologies, 11(2): 213-218.

\section{Authors}

Radha D working as an Assistant professor in the Department of Computer Science Engineering at HKBK College of Engineering, Bengaluru, Karnataka, India. She received her B.E. degree in Information Science and Engineering from Yellamma Dasappa Institute of Technology, Bengaluru, in 2012, which is affiliated to Visvesvaraya Technological University (VTU). She completed her M.E degree in Computer Science and Engineering from AMC Engineering College, Bengaluru, in 2016, which is affiliated to Visvesvaraya Technological University (VTU). Email: radhad10391@gmail.com

Dr. M Arun Kumar is working as an Assistant professor in the Department of Electrical, Electronics \& Communication Engineering at GITAM School of Technology, 
Bengaluru Campus, Bengaluru, India. He completed his Bachelor's degree in Electronics \& Communication Engineering from Anna University, Chennai, India, in 2010. He acquired his Masters in VLSI Design from Kongu Engineering College, Anna University, India, in 2012. He completed his Ph.D. degree from Anna University. Email: manokavi2011@gmail.com

Nagarjuna Telagam is with the Electronics and Communication Engineering Department, GITAM, Bangalore, India. He is a Research Scholar at Sathyabama University. He received his B. Tech degree from JNTU University/ Narayana Engineering College. He received his master's degree from Anna University/ Loyola Institute of Technology. He is Anna University rank holder (20) for Masters in Engineering degree in 2013. He published more than 30 papers in Scopus Indexed Journals and SCIE indexed journals. Email: nagarjuna473@gmail.com

Mr. M. Sabarimuthu is working as an Assistant Professor in the Electrical and Electronics Engineering Department at Kongu Engineering College, Perundurai, India. $\mathrm{He}$ is currently pursuing his research under the supervision of Professor N. Senthilnathan from the same institution. He completed his undergraduate in Engineering from Anna University, Chennai, India, in 2009. He acquired his master's degree in Applied Electronics at Kongu Engineering College, Perundurai, in 2012. Email: eeesabari@gmail.com@gmail.com

Article submitted 2020-10-14. Resubmitted 2020-11-23. Final acceptance 2020-11-24. Final version published as submitted by the authors. 